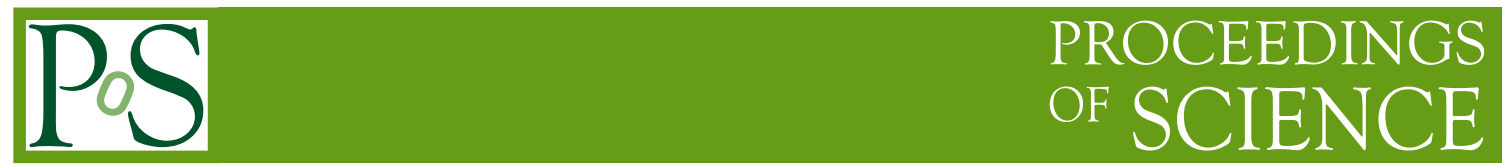

\title{
Top production at the LHC
}

\author{
Jordi Nadal* \\ II. Physikalisches Institut \\ E-mail: jordi.nadalecern.ch
}

Latest LHC results of the top quark production are presented. With the focus on the ATLAS and CMS experiment I will present top quark production cross-section in the different channels and also the latest results on the single top production, giving the state-of-art measurements. I also include differential cross-section as well as top quark pair production in association with W/Z bosons.

Frontiers of Fundamental Physics 14 - FFP14,

15-18 July 2014

Aix Marseille University (AMU) Saint-Charles Campus, Marseille

${ }^{*}$ Speaker. 